\title{
Assessment of polyphenol content and antioxidant activity of oak bark extracts
}

\author{
Paulina Dróżdż $\dot{1}^{1}$ Krystyna Pyrzynska²
}

Received: 28 August 2017 / Published online: 19 December 2017

(c) The Author(s) 2017. This article is an open access publication

\begin{abstract}
Extraction efficiency of total polyphenols and flavonoids from bark oak (Quercus robur L.) grown in the central region of Poland was evaluated. The total phenolics of water and 60\% ethanol and extracts were in the range of 55.4-60.4 and $71.0-79.3 \mathrm{mg}$ gallic acid/g of bark, respectively, while the total flavonoid content in these extracts were determined in the range of 35.1-38.0 and 72.0-78.4 mg catechin/g. The hydroalcoholic extracts exhibited higher DPPH radical scavenging activity than BHT (butylated hydroxytoluene), popular food additives.
\end{abstract}

\section{Introduction}

Bark is known to also accumulate large amounts of polyphenolic compounds which exhibit a wide range of biological effects, including antioxidant, antibacterial and anti-inflammatory activity (Ferreira et al. 2015; Dedrie et al. 2015). Oak bark due to its valuable chemical composition, has been used in traditional medicine for the treatment of wounds and skin diseases.

Abundant and inexpensive materials, such as residues of wood transformation, represent a promising source for natural antioxidant substances (Bouras et al. 2015; Jung et al. 2016; Lazar et al. 2016). The aim of this study was to evaluate the extraction of major classes of polyphenolic compounds from bark oak (Quercus robust L.) grown in the central region of Poland along with the DPPH radical scavenging activity of these extracts.

\section{Materials and methods}

Oak bark (Quercus robur L.) samples were collected in two different locations in central Poland (the Mazovia plain). The sample S1 was from 12-year old pine forest (N 52 $41^{\prime}$,

Krystyna Pyrzynska

kryspyrz@chem.uw.edu.pl

1 Forest Research Institute, Laboratory of Natural Environment Chemistry, Sękocin Stary, Poland

2 Department of Chemistry, University of Warsaw, Pasteura 1, Warsaw, Poland
E $21^{\circ} 29^{\prime}$ ) and the sample S2 from 25-year old pine forest (N 52 $49^{\prime}, \mathrm{E} 21^{\circ} 45^{\prime}$ ). The collected plant material was dried at $40{ }^{\circ} \mathrm{C}$ for $24 \mathrm{~h}$, then ground (Pulverisette 15 ) and sieved $(0.5 \mathrm{~mm})$. The commercially available oak bark sample (Herbapol, Poland) purchased from a local drugstore was used for comparison (sample S3). The dry plant material (700 mg) was mixed with $25 \mathrm{~mL}$ of ethanol-water solution $(60: 40, \mathrm{v} / \mathrm{v})$ for $20 \mathrm{~min}$ at room temperature.

The total phenolic content was evaluated using Folin-Ciocalteu (FC) assay. $0.1 \mathrm{~mL}$ of sample was mixed with $0.1 \mathrm{~mL}$ of $\mathrm{FC}$ reagent and $0.9 \mathrm{~mL}$ of water. After $5 \mathrm{~min}, 1 \mathrm{~mL}$ of $7 \% \mathrm{Na}_{2} \mathrm{CO}_{3}$ and $0.4 \mathrm{~mL}$ of water were added and the mixture was incubated for $30 \mathrm{~min}$. Absorbance was measured at $765 \mathrm{~nm}$ against the reagent blank.

For the determination of total flavonoid content, $1 \mathrm{~mL}$ of a sample was mixed with $0.3 \mathrm{~mL}$ of $\mathrm{NaNO}_{2}(5 \%$, w/v) and after $5 \mathrm{~min} 0.5 \mathrm{~mL}$ of $\mathrm{AlCl}_{3}(2 \%, \mathrm{w} / \mathrm{v})$ was added. A sample was mixed and 6 min later neutralized with $0.5 \mathrm{~mL}$ of $1 \mathrm{M}$ $\mathrm{NaOH}$ solution. The mixture was left for $10 \mathrm{~min}$ at room temperature, and then absorbance was recorded at $510 \mathrm{~nm}$.

The diphenylpicrylhydrazyl (DPPH) assay was applied to estimate the radical-scavenging ability of the oak bark extracts as described elsewhere (Pękal and Pyrzynska 2013).

\section{Results and discussion}

Water and ethanol-water solution $(60: 40, \mathrm{v} / \mathrm{v})$ were used for extraction of phenolic compounds from bark oak samples. The results for total phenolic (TP) and total flavonoid (TF) contents in the studied extracts are shown in Table 1. As 
Table 1 Total phenolic (TP) and flavonoid (TF) contents in the oak bark extracts

\begin{tabular}{llll}
\hline Sample & S1 & S2 & S3 \\
\hline \multicolumn{2}{l}{ Water extraction } \\
TP & $55.4 \pm 1.6^{\mathrm{a}}$ & $56.4 \pm 0.1^{\mathrm{a}}$ & $60.4 \pm 1.3^{\mathrm{b}}$ \\
TF & $35.1 \pm 0.2^{\mathrm{a}}$ & $33.1 \pm 0.8^{\mathrm{a}}$ & $38.0 \pm 1.1^{\mathrm{b}}$ \\
Ethanol-water extraction & & \\
TP & $76.0 \pm 0.8^{\mathrm{a}}$ & $79.3 \pm 0.8^{\mathrm{a}}$ & $71.0 \pm 1.5^{\mathrm{b}}$ \\
TF & $72.3 \pm 2.3^{\mathrm{a}}$ & $72.0 \pm 0.9^{\mathrm{a}}$ & $78.4 \pm 0.8^{\mathrm{b}}$ \\
\hline
\end{tabular}

Flavonoid content expressed in $\mathrm{mg}$ of catechin/g

Values represent mean $\pm \mathrm{SD}(\mathrm{n}=3)$

$T P$ total phenolic content expressed in $\mathrm{mg}$ of gallic acid/g; $T F$ total

${ }^{\mathrm{a}, \mathrm{b}}$ Means with different superscript letters in each row are significantly different at $p<0.05$ (ANOVA, followed by Turkey's test)

expected, extraction yields with ethanol-water mixture were higher than those obtained by water, particularly for total flavonoid content, probably due to higher solubility of these compounds in alcohols. However, taking into account the use of hot water extract of oak bark by folk medicine, the TP values obtained for these extracts are higher in comparison with the values (10.5-13.4 $\mathrm{mg}$ gallic acid/g) reported for the bark of oak species $Q$. robur $\mathrm{L}$. and $Q$. petraea grown in Wallonia region, Belgium (Dedrie et al. 2015). The results of one-way ANOVA followed by Turkey's test indicated that TP and TF contents for samples S1 and S2 with different oak ages were statistically similar $(p<0.05)$ for water as well as ethanol-water extractants. The comparison between the sampled oak bark extracts (sample S1 and S2) with commercially available dry oak bark (sample S3) demonstrates that the latter contains a little bit higher amounts of total phenolic and flavonoid contents, except the TP value in ethanol-water extract, which is significantly higher for S1 and S2 samples.

Antioxidant activity of the studied extracts was assessed on the basis of their scavenging effect on the stable DPPH radical. The kinetic curves of scavenged DPPH by water and ethanol-water extracts of sample S2 as an example is presented in Fig. 1. During the first few minutes of the reaction, significant decrease in the absorbance of DPPH was observed, followed by slow subsequent disappearance of the reagent. The kinetic curves for butylated hydroxytoluene (BHT), popular synthetic antioxidant used as a food additive, at its concentration of $50 \mu \mathrm{M}$, are also presented in Fig. 1 for comparison. As could be seen, the studied extracts of $Q$. robur bark exhibited similar or higher (hydroalcoholic solution) DPPH radical quenching than BHT solution. To the best of the authors' knowledge, the antioxidant activity of $Q$. robur extract using ethanol-water mixture has not been reported yet. Only polyphenols yields have been determined (Dedrie et al. 2015; Bouras et al. 2015). Galiňanes et al. (2015) found that $2 \% \mathrm{Na}_{2} \mathrm{SO}_{3}$ extract from $Q$. robur bark

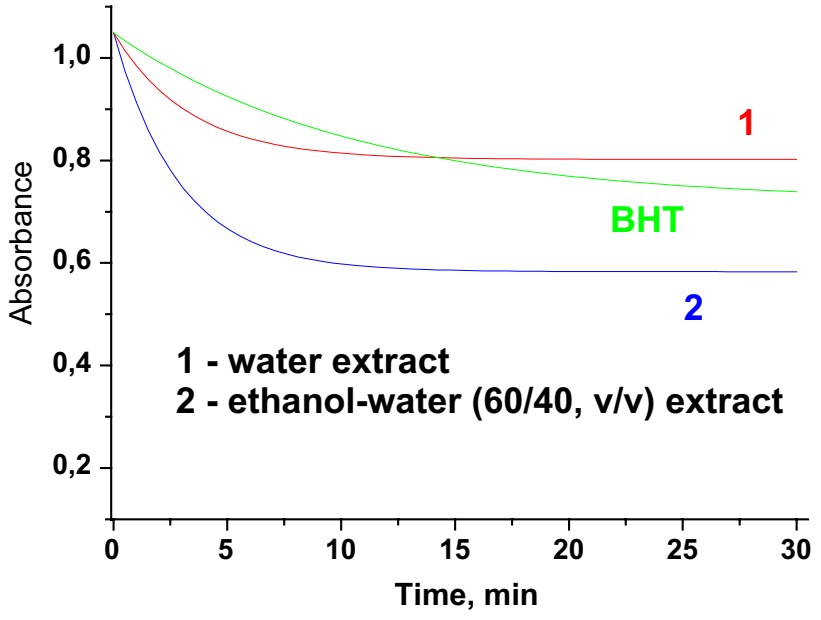

Fig. 1 Kinetic curves of scavenged DPPH by extracts of $Q$. robur

grown in Spain had higher DPPH radical scavenging activity $\left(\mathrm{EC}_{50}=0.063 \mathrm{mg} / \mathrm{mL}\right)$ than water extract $\left(\mathrm{EC}_{50}=0.074 \mathrm{mg} /\right.$ $\mathrm{mL})$.

The present results showed that the crude bark extracts of Quercus robur, considered as forest industry residues, contained high content of biophenols and exhibit high antioxidant properties. The extracts can be obtained by simple extraction procedures directly from the existing waste raw material, reducing the need for additional processing stage and could find applications as additives in nutraceutical and cosmetic products to prevent damage provoked by oxidative stress in human organism.

Acknowledgements The authors would like to thank Forest Research Institute for financial support given to the project 'The possibility of utilization of non-wood forest products (NWFPs) as a source of antioxidants in beneficial for health supplements', topic no. 260801.

\section{Compliance with ethical standards}

Conflict of interest The authors declare that they have no conflict of interest.

Open Access This article is distributed under the terms of the Creative Commons Attribution 4.0 International License (http://creativecommons.org/licenses/by/4.0/), which permits unrestricted use, distribution, and reproduction in any medium, provided you give appropriate credit to the original author(s) and the source, provide a link to the Creative Commons license, and indicate if changes were made.

\section{References}

Bouras M, Chadni M, Barba FJ, Grimi N, Bals O, Vorobiev E (2015) Optimization of microwave-assisted extraction of polyphenols from Quercus bark. Ind Crop Prod 77:590-601 
Dedrie M, Jacquet N, Bombeck PL, Hébert J, Richel A (2015) Oak barks as raw materials for the extraction of polyphenols for the chemical and pharmaceutical sectors: a regional study. Ind Crop Prod 70:316-321

Ferreira JPA, Miranda I, Gominho J, Pereira H (2015) Selective fractioning of Pseudotsuga menziesti bark and chemical characterization in view of an integrated valorization. Ind Crop Prod 74:998-1007

Galiňanes C, Freire MS, González-Ălvarez J (2015) Antioxidant activity of phenolic extracts from chestnut fruit and forest industries residues. Eur J Wood Prod 73:651-659
Jung JY, Park HM, Yang JK (2016) Optimization of ethanol extraction of antioxidative phenolic compounds from torrefied oak wood (Quercus serrata) using response surface methodology. Wood Sci Technol 50:1037-1055

Lazar L, Talmaciu AI, Volf I, Popa VI (2016) Kinetic modelling of the ultrasound-assisted extraction of polyphenols from Picea abies bark. Ultrason Sonochem 32:191-197

Pękal A, Pyrzynska K (2013) Application of free radical diphenylpicrylhydrazyl (DPPH) to estimate the antioxidant capacity of food samples. Anal Meth 5:4288-4295 